\title{
PREFABRICATION AS A SUSTAINABLE MODEL IN RAIL CONSTRUCTION: A RESEARCH ENQUIRY
}

\author{
ARASH AHMADI, MAGED GEORGY, MALIK KHALFAN, and TAYYAB MAQSOOD \\ School of Property, Construction and Project Management, RMIT University, \\ Melbourne, Australia
}

\begin{abstract}
In many construction projects, prefabrication has proven to benefit sustainability. This innovative construction practice can virtually extend the life of assets while minimizing costs and time and enhancing quality and safety. In rail construction, prefabrication has long been utilized for certain elements of the rail assets but not all. The paper reports on the initiation of a research to investigate the contribution and potential of prefabrication to increasing sustainability and the whole lifecycle benefits in the rail construction industry in Australia. Paper embraces a broad definition of the term "sustainability" which includes energy and water efficiency, health and safety, durability and quality, pollution and waste reduction, overall cost and time efficiency, and sustainable society/community. The research adopts a qualitative case study approach that employs Soft Systems Methodology (SSM) for examining the research enquiry. A variety of stakeholders will be interviewed in each project case besides reviewing the archived content. Stakeholders including construction contractors, rail operators and maintainers, end-users, government bodies, and those involved with the project's supply chain will benefit from having a more transparent and clear understanding of the effect of prefabrication on the sustainability of rail assets.
\end{abstract}

Keywords: Industrialization, Prefabrication, Off-site production, Rail construction projects, Soft system methodology (SSM).

\section{INTRODUCTION}

Rail construction projects can be viewed as reaction to economic, political and social needs of communities and industries alike (Geyer and Davies 2000). Hence, they play a critical role in our lives. The question that arises is how to deliver such projects in a sustainable way. Sustainability in the construction industry has become a major challenge because of the construction activities' permanent environmental impacts (Jaillon et al. 2009). Rail infrastructure development requires construction works that result in production of different types of wastes, emission of $\mathrm{CO} 2$, depletion of natural resources, besides the long-term effects on the social and economic aspects of a society (Nye 2011). Therefore, there is a need to undertake more sustainable methods in rail construction that have the ability to enhance the utilization of resources while reducing cost, waste, safety concerns, and future impacts on the environment (Othman 2010).

According to Buys et al. (2005), any innovative design or construction methodology towards a sustainable practice can provide social, environmental and economic benefits. Many academics have promoted methodologies such as prefabrication and off-site production (in general industrialization) to enhance the level of 
sustainability in the construction industry (Blismas and Wakefield 2009). Yet, when it comes to rail construction, further exploration is needed to enhance the current knowledge and our understanding of what and how to deliver sustainable rail infrastructure assets.

A research was initiated by the authors to investigate the contribution and potential of prefabrication practices to increasing sustainability and the whole lifecycle benefits in the rail construction industry in Australia. The research will undertake a qualitative case study approach. The paper reports on the preliminary research enquiry. It is envisioned that several entities in the Australian Rail Construction market, such as, the Australian Federal/State Government, the Australasian Railway Association (ARA) Rail Contractors Group (RCG), Rail Manufacturers Group (RMG), and Rail Suppliers Network Australasia (RSNA), will benefit from this research when complete.

\section{BACKGROUND}

Rail construction projects are part of the overall construction industry, and typically comprise construction works such as tracks, power supply, signaling systems, stabling yards, stations, car parks, etc. Similar to other infrastructure assets, there is a range of stakeholders that take part in project delivery including operators, suppliers, maintainers, government parties, banks, unions, safety authorities, environmental/heritage authorities, designers, contractors and the public (Geyer and Davies 2000).

Construction activities, in general, have a major impact on the environment. Consider, for example, the waste generated from construction works. In 2003, waste generated from excavation and demolition activities in UK reached approximately 91 million tons (Osmani et al. 2008). Construction industry is also known to be a prime consumer of energy and natural resources, and thus plays a vital role in achieving or hindering sustainability (Jaillon et al. 2009).

Sustainability is still an evolving area of knowledge. According to Aguado et al. (2011), the sustainability domain is not well-grounded yet and involves a variety of assessment factors that are desirable. In an early publication by Holmberg (1992), it was noted that sustainability had been defined in approximately 70 different ways. However, in general terms, there has been certain consensus that sustainability is a solution to enhance the use of resources and consider future needs and the environment while achieving today's needs (Othman 2010). To infuse sustainability principles into real industry application, environmental evaluation tools, such as, BEES 4.0, LEED ${ }^{\circledR}$, EQUER, LEGEP ${ }^{\circledR}$, BeCost, ATHENA ${ }^{\mathrm{TM}}$, NABERS, etc., have been developed in the last two decades to assess specific components in a building or the whole building's frameworks. The assessment may include any phase of the built environment's life cycle, e.g., material manufacturing, demolition, construction, recycling, and so on. The assessment tools - no matter international or local-were developed to focus on specific needs, for instance, commercial, maintenance, academic, or else. The positive side to such diversity was the ability to cater to a wide array of customer groups; however, the drawback is the difficulty of reconciling the differences amongst them (Haapio and Viitaniemi 2008).

Unfortunately, when it comes to real life practice, the majority of actions in construction still have some permanent impact on the environment. There is a call to 
reduce such impact via alternative actions that have more sustainable elements (Aguado et al. 2011). This is not untrue for the Australian context as well. According to Luther (2009), existing construction methodology within the Australian construction market, including the rail industry, does not comply with sustainable practices in terms of enhancing resources or reducing energy consumption. Majority of construction works use traditional materials such as concrete, steel and brick in-situ. Waste typically results from poor site management, misunderstanding of designs and material schedule, construction and/or on-site actions (Osmani et al. 2008). The Australian market is truly keen to undertake more efficient and sustainable solutions (Luther 2009).

Would industrialization be the answer! In the building industry, Industrialized Building Systems (IBS) are recognized as a different construction technique that helps obtain sustainable building solutions. The IBS engages techniques such as prefabrication and off-site manufacturing to minimize unforeseen complications from weather conditions, sagging labor productivity, design disasters, and road traffic conditions for material transportation. Some academics view IBS construction as a strategic resolution to decreasing construction surplus into the environment. IBS is a major method in enhancing sustainability by minimizing wastes and use of resources. The typical waste reduction through using IBS is in the vicinity of $52 \%$, which is a significant value when compared to other procedures (Yunus and Yang 2011). In comparison, traditional on-site techniques are criticized for being laborious, noncompliant with health and safety requirements and being a major damage to the environment (Yunus and Yang 2011). Furthermore, the on-site operations constantly create annoyances to the public and neighborhoods, through traffic problems, dust, and noise (Yee 2001).

\section{RESEARCH FOCUS}

The current research attempts to investigate and better understand the contribution and potential benefits of prefabrication and industrialization practices to increasing the sustainability and whole lifecycle benefits in rail construction projects in Australia. However it was important to embrace a broad definition of sustainability in rail construction projects, and which includes six measures: (1) energy and water efficiency, (2) health and safety, (3) durability and quality, (4) pollution and waste reduction, (5) Sustainable society/community [which translates into sustained career opportunities], and (6) Overall cost and time efficiency.

Prefabrication and industrialization in this context will cover industry practices such as off-site production (OSP), off-site manufacturing (OSM), industrialised building systems (IBS) and pre-assembly. It will span the whole construction process and address the various management strategies and practice frameworks in place. The research will attempt to keep this investigation in line with the practical needs of design firms, engineers, construction contractors, builders, rail operators, maintainers, the government, and supply chain business entities. Research enquiries will aim to tackle existing construction problems such as the total construction time, limitations on the work hours around the rail operating times, safety concerns, budget availability, human resource challenges, environmental issues, growing demand for transport infrastructure, 
and the persistent lag in quality that can affect the lifecycle sustainability of the project. The research targets the following sub-objectives:

- Revealing the current status of sustainability in the rail construction industry.

- Examining the general efficiency of prefabrication in rail construction in terms of the six sustainability measures into consideration.

- Examining the efficiency of prefabrication in rail construction for selected rail infrastructure elements/assets and undertaking a comparison with the traditional counterparts.

- Identify the rail construction stakeholders and the criteria that drive selection of a certain construction method over the others.

- Identify the mechanism by which sustainability can be enhanced in the long term.

- Investigate how value for money can be ensured in replacing of the current traditional construction methods with the prefabrication approaches.

\section{RESEARCH METHODOLOGY}

This study adopts a qualitative case study approach. Five different and diverse case studies in the Australian rail construction industry will be selected and analyzed in depth. Each case study, that is a rail project, will have undertaken prefabrication methods during the project delivery process. Data will be collected from archived documents and interviews with candidates from different stakeholder organizations involved in each project case.

The SSM will form the foundational basis for conducting the research and drawing conclusions out of the case studies. The SSM will help establish/model an ideal situation for adopting prefabrication in rail construction and allow comparisons with the real-world scenarios. SSM was developed by Peter Checkland in 1970. It is an approach to search, demand and acquire-about a problem then model an ideal type of structured behavior to compare with the real world issue. Finally, feasible changes to improve the situation are recommended (Lane and Oliva 1998). In 1981, a seven-stage process was devised by Checkland, Figure 1. As per Checkland (2000), stages 1 and 2 involve finding and stating the problem including a big picture and activity systems. Stage 3 defines the problem root while in Stage 4 a model takes shape to express the situation. Stage 5 uses the developed model to dig further and compare the condition with the ideal situation. Defining desirable and feasible changes to enhance the condition in the real world follows in Stage 6. Stage 7 undertakes the indicated actions to enhance the condition and the cycle continues. The current research will be based on this 7-step process.

\section{RESEARCH INSTRUMENTS}

Different instruments will be employed in this research including: (1) archived document review, (2) interviews, and (3) focus group. For each project case into consideration, the archived documents will be examined. Furthermore, candidates from 
the stakeholder organizations involved in each case study will be interviewed to obtain a picture of the industry practices in place and to define the existing problems. According to Morgan (1996) and Marczak and Sewell (2006), ideally five to twelve participants will be selected; however, the final number will be subject to accessibility and which stakeholder organizations the researchers find most beneficial to obtain information from in each case study.

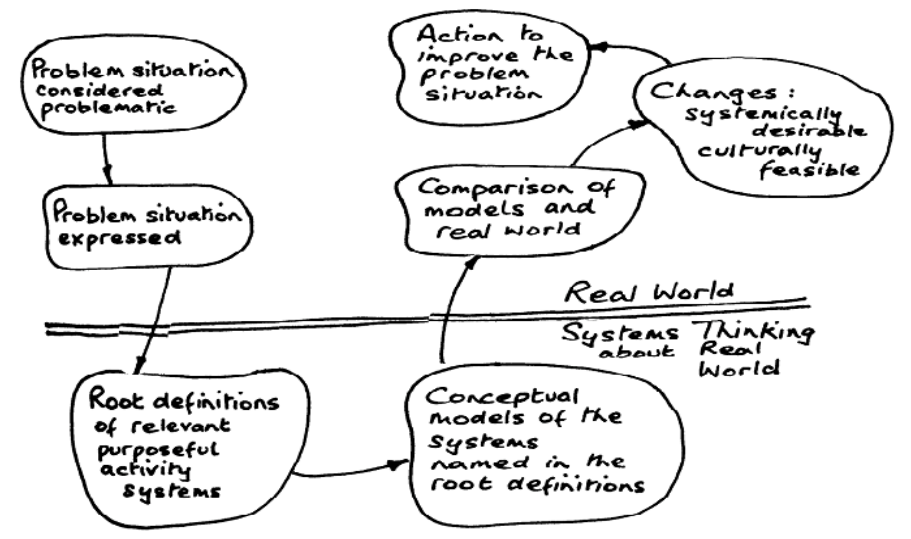

Figure 1. Seven steps of the SSM (Checkland 2000).

To manage the interviews, a guide will be prepared by the interviewer/researcher in advance with a chain of questions and reminders for researcher to ensure the interview has a roadmap and maintains focus. Data captured regarding each case study will include details on costs, timeframes, resource consumption, energy savings, social opportunities, safety, quality control, $\mathrm{CO} 2$ production, hand-overing, among others. The analysis, which is considered an ongoing learning process, will employ the likes of NVIVO. Responses will be summarized to create the base to compare the current academic views and those undertaken as real world practices to model opportunities and required actions and changes to improve the situation toward an ideal situation (Maqsood et al. 2006).

At the end of this research, a focus group will be arranged to capture the collective insights of a selected panel of rail industry practitioners into the different perspectives emerging from the 5 case studies and help evaluate and interpret the results as well.

\section{CONCLUSIONS}

The extensive literature review revealed the importance of the rail construction industry both worldwide and locally. Industrialization has also been promoted as a sustainable solution in different construction practices. This instigated the need for a comprehensive and more detailed research to better understand whether prefabrication and industrialization in general would enhance the sustainability and whole lifecycle benefits in the rail construction industry in Australia. It was however important to have a more holistic and broad interpretation of the term sustainability to include the likes of 
social sustainability, economic sustainability, besides the more conventional environmental sustainability. Selection of the SSM stemmed from the methodical approach it provides in drawing a big picture of the practice in existence and provides basis for comparison with the ideal situation. In running the interviews the researchers will approach the task without any presumptions and/or initial hypotheses to ensure the qualitative analysis is unbiased.

\section{References}

Aguado, A., Caño, A., de la Cruz, M., Gómez, D., and Josa, A., Sustainability Assessment of Concrete Structures Within the Spanish Structural Concrete Code, Journal of Construction Engineering and Management, ASCE, 138(2), 268-276, 2011.

Blismas, N., and Wakefield, R., Engineering Sustainable Solutions through Off-site Manufacture, In Technology, Design and Process Innovation in the Built Environment, Newton, P., Hampson, K., and Drogemuller, R. (Eds.), 355-370, 2009.

Buys, L., Barnett, K., Miller, E., and Bailey, C., Smart Housing and Social Sustainability: Learning from the Residents of Queensland's Research House, Australian Journal of Emerging Technologies and Society, 3(1), 43-57, 2005.

Checkland, P., Soft Systems Methodology: A Thirty Year Retrospective, Systems Research and Behavioral Science, 17, S11-S58, 2000.

Geyer, A., and Davies, A., Managing Project-System Interfaces: Case Studies of Railway Projects in Restructured UK and German Markets, Research Policy, 29(7), 991-1013, 2000.

Haapio, A., and Viitaniemi, P., A Critical Review of Building Environmental Assessment Tools, Environmental Impact Assessment Review, 28(7), 469-482, 2008.

Holmberg, J. Making Development Sustainable: Redefining Institutions Policy and Economics, Island Press, 1992.

Jaillon, L., Poon, C, and Chiang, Y., Quantifying the Waste Reduction Potential of Using Prefabrication in Building Construction in Hong Kong, Waste Management, 29(1), 309-320, 2009.

Lane, D., and Oliva, R., The Greater Whole: Towards a Synthesis of System Dynamics and Soft Systems Methodology, European Journal of Operational Research, 107(1), 214-235. 1998.

Luther, M., Towards Prefabricated Sustainable Housing - An Introduction, BEDP Environment Design Guide, Vol. TEC 28, 1-11, 2009.

Maqsood, T., Finegan, A., and Walker, D., Applying Project Histories and Project Learning through Knowledge Management in an Australian Construction Company, The Learning Organization, 13(1), 80-95, 2006.

Marczak, M., and Sewell, M., Using Focus Groups for Evaluation, The University of Arizona, Tuscon, AZ, 2006.

Morgan, D., Focus Groups, Annual Review of Sociology, 22, 129-152, 1996.

Nye, B., The True Value of Rail, Deloitte Access Economics, The Australasian Railway Association, 2011.

Osmani, M., Glass, J., and Price, A., Architects' Perspectives on Construction Waste Reduction by Design, Waste Management, 28(7), 1147-1158, 2008.

Othman, A., Incorporating Innovation and Sustainability for Achieving Competitive Advantage in Construction, In Industrialised, Integrated, Intelligent sustainable Construction, Wallis, I., Bilan, L., Smith, M., and Kazi, A. (Eds.), 13-42, 2010.

Yee, A., Social and Environmental Benefits of Precast Concrete Technology, PCI Journal, 46(3), 14-19, 2001

Yunus, R., and Yang, J., Sustainability Criteria for Industrialised Building Systems (IBS) in Malaysia, Procedia Engineering, 14, 1590-1598, 2011. 